\title{
The European Community Study Group on Diagnostic Criteria for Sjögren's Syndrome. Sensitivity and specificity of tests for ocular and oral involvement in Sjögren's syndrome
}

\author{
Claudio Vitali, Haralampos M Moutsopoulos, Stefano Bombardieri, and The European \\ Community Study Group on Diagnostic Criteria for Sjögren’s Syndrome*
}

\begin{abstract}
Aim-To establish a definitive set of diagnostic criteria in a multicentre European study a selected number of oral and ocular tests were performed on a large number of patients with Sjögrens Syndrome (SS) and controls. The diagnostic accuracy of each test for patients with primary and secondary SS and for controls at different ages, was studied.

Methods-Each centre received a clinical chart describing the series of tests to be conducted. The tests included: questionnaires for dry eye and dry mouth symptoms, Schirmer's-I-test (ScT), tear fluid lactoferrin level (TFLL), break-up time (BUT) and rose Bengal score (RBS) for the eye evaluation; unstimulated and stimulated whole saliva collection (UWSC and SWSC), salivary gland scintigraphy (SGS), parotid sialography (PS) and minor salivary gland biopsy (MSGB) for oral involvement.
\end{abstract}

Results-Data from 22 centres and 11 countries was collected on a total of 447 patients with SS (246 with primary SS and 201 with secondary SS) and 246 controls (of whom 113 had a connective tissue disease without SS). Among the ocular symptoms, the feeling of dry eye and 'sand in the eye' were the ones most commonly recorded in patients with SS. Similarly, the feeling of dry mouth, appearing either spontaneously or when the patient was eating or breathing, was the most frequent subjective oral symptom. Among the ocular tests, ScT showed the best balance between sensitivity and specificity (76.9\% and $72.4 \%$ respectively), while $\mathrm{RBS}$ was the most specific test $(81 \cdot 7 \%)$. ScT and RBS gave also sufficiently concordant results. TFLL and BUT gave considerably less reliable results, which were not concordant with each other or with the other ocular tests. The quantitative lacrimal tests ScT and TFLL produced significantly different results in elderly controls, while RBS did not. Abnormal results for all of the ocular tests were less marked and less frequent in patients with secondary SS than in those with primary SS. The oral tests (except SWSC) were generally more reliable than the ocular tests in diagnosing SS. In particular, PS was the most specific diagnostic tools $(100 \%)$, while MSGB (where the presence of at least one inflammatory focus was considered as indicative for the diagnosis) showed a good balance between sensitivity and specificity $(82 \cdot 4 \%$ and $86 \cdot 2 \%$, respectively). The tests showed a good degree of agreement and, with the exception of UWSC, were not influenced by age. In the oral, as in the ocular tests, abnormal results were less frequent and less marked in patients with secondary SS.

Conclusions-The results clearly show that ScT and RBS (for the eye evaluation), and SGS, PS, MSGB and UWSC (for salivary gland involvement) are the most reliable tests for the diagnosis of SS. The clinician should be aware, however, that the test results may vary depending on the age of the patient and the type of SS (primary or secondary).

(Ann Rheum Dis 1994; 53: 637-647)

Many diagnostic tests exist to assess salivary and lacrimal involvement in Sjögren's syndrome (SS), but there is still disagreement regarding their sensitivity and specificity. ${ }^{1-3}$ Thus different sets of classification criteria, based on different combinations of tests, have been suggested ${ }^{4-7}$ and no consensus has yet been reached, even though the need for a definitive set of diagnostic criteria is widely recognised, ${ }^{8}$ such as that established by the American Rheumatism Association for other connective tissue diseases. ${ }^{9-11}$

A multicentre study supported by the Epidemiology Committee of the European Community (EEC-COMAC Epidemiology) was therefore carried out to assess the sensitivity and specificity of various tests as diagnostic tools for SS, and to formulate a universally acceptable diagnostic criteria to be used in future studies. In this paper we present a detailed report of the results obtained in this European study, and in particular on the sensitivity and specificity of each of the ocular and salivary tests included in the study protocol. A set of preliminary classification criteria 
Table 1 Questionnaire for eye involvement in Sjogren's syndrome

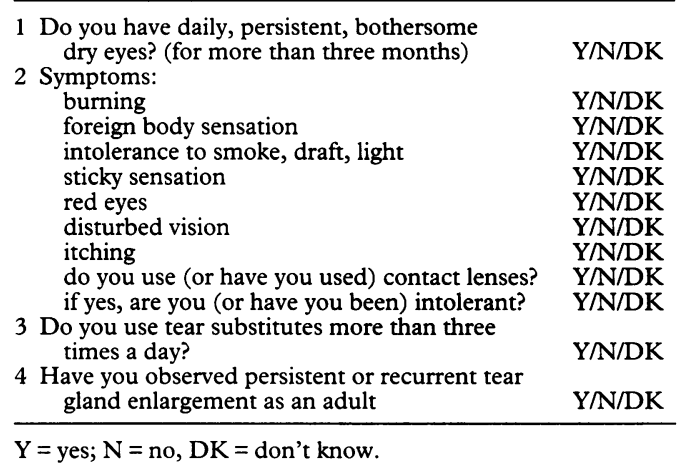

for SS derived from a multivariate analysis of the data collected for this study has already been published. ${ }^{12}$

\section{Materials and methods}

STUDY PROTOCOL

During a preliminary workshop held in Pisa, Italy in 1988, 29 experts from 12 countries compared their experience in the field of SS and established the study design. A clinical chart was carefully prepared and distributed to all of the participating centres for the data collection. Besides the sections for the clinical and serological evaluation of the patients, the clinical chart included: (A) a questionnaire for subjective eye symptoms (table 1); (B) a form with the tests for the ophthalmological examination; (C) a questionnaire for subjective oral symptoms (table 2); and (D) a form with the tests for the assessment of oral involvement. A limited number of diagnostic tests for oral and ocular involvement were selected to be validated, and included in the respective forms (sections B and D). The precise procedures to be used in performing these tests was also defined. ${ }^{13}$ The following tests were included: (1) Schirmer's-I-test (ScT), rose Bengal score (RBS), break up time (BUT) and the tear fluid lactoferrin level (TFLL) for the eye evaluation; and (2) unstimulated and stimulated whole saliva collection (UWSC and SWSC), minor salivary gland biopsy (MSGB), parotid sialography (PS) and salivary gland scintigraphy (SGS) for oral involvement.

ScT was to be performed using standardised tear test strips, placed for five minutes between the eyeball and the most lateral part of the

Table 2 Questionnaire for oral involvement in Sjogren's syndrome

\begin{tabular}{|c|c|}
\hline $\begin{array}{l}\text { Have you had a daily feeling of dry mouth for } \\
\geqslant \text { three months? } \\
\text { Do you have difficulties in swallowing dry food } \\
\text { (for instance, crackers) because of dryness } \\
\text { of your mouth? } \\
\text { Do you carry water or a saliva substitute or do } \\
\text { you need water or a saliva substitute at night? } \\
\text { Have you had recurrently or persistently } \\
\text { swollen salivary glands as an adult? } \\
\text { Do you frequently drink liquids to aid in } \\
\text { swallowing dry food? } \\
6 \text { Does your mouth feel dry when eating or } \\
\text { breathing? } \\
7 \text { Have you ever had a fungal infection in your } \\
\text { mouth? }\end{array}$ & $\begin{array}{l}\text { Y/N/DK } \\
\text { Y/N/DK } \\
\text { Y/N/DK } \\
\text { Y/N/DK } \\
\text { Y/N/DK } \\
\text { Y/N/DK } \\
\text { Y/N/DK }\end{array}$ \\
\hline
\end{tabular}

$\mathrm{Y}=$ yes; $\mathrm{N}=$ no, $\mathrm{DK}=$ don't know. inferior lid, without using previous anaesthetic eyedrops. The patient was to sit with the eyes closed, but not squeezed tight. After five minutes the length of the wetted area of the strip was measured, starting from the notch corresponding to the inferior lid margin. ${ }^{14}$

RBS was to be performed by placing $25 \mu \mathrm{l}$ rose Bengal solution in the inferior fornix of each eye and asking the patient to make 1-2 full blinks. Afterwards the number of red spots was counted and scored: 1+ (sparsely scattered), $2+$ (densely scattered), or $3+$ (confluent) in three different areas, that is, the lateral and nasal conjunctiva, and the cornea. The sum of the scores from the three regions of one eye formed the RBS of that eye. ${ }^{15}$

BUT was to be carried out by placing $25 \mu \mathrm{l}$ of a $1 \%$ fluorescin solution in the inferior fornix of each eye and asking the patient to make 1-2 full blinks. Using a slit lamp, the interval between the last blink and the formation of growing black holes in the fluorescinated tear fluid was measured by a stop watch. ${ }^{16}$

TFLL was to be measured using a lactoplate kit (JDC, Culemborg, The Netherlands). Briefly, a paper disc was placed in the lateral part of the inferior fornix of each eye and removed when completely damp (usually after less than five minutes). Each disc was then transferred to its corresponding reagent gel in the lactoplate kit and left for three days at room temperature. The diameter of the precipitate ring was then measured and the lactoferrin concentration calculated using the table provided in the kit. ${ }^{17}$

The specific sequence for the performance of the four tests for eye involvement was indicated: (1) BUT; (2) ScT; (3) TFLL; (4) RBS. This had been established beforehand by the ophthalmologists in the European Community Study Group to avoid the possibility of one test influencing the results of the following one. ${ }^{13}$

UWSC and SWSC were to be performed between 9 and 11 am with the patients fasting and no brushing of teeth, mouth rinsing, or smoking of tobacco for at least one hour before the procedures were carried out. The patient was to be seated, inclining forward slightly, during the tests. The saliva was collected in conical calibrated tubes; stimulation was induced by asking the patient to chew on a $2 \mathrm{~g}$ paraffin block. Collection time was 15 minutes for the unstimulated test and five minutes for the stimulated test. ${ }^{18}$

MSGB was to be performed according to the procedure suggested by Daniels. ${ }^{19}{ }^{20}$ After local anaesthesia, a $2 \mathrm{~cm}$ incision was made parallel to the vermillon border in the middle of the lower lip, between the midline and the corner of the mouth. At least five lobes of labial glands were to be obtained by blunt dissection. All of the glands were then embedded along the same plane in paraffin, to provide midplane sections through all glands. Sections $3-5 \mathrm{~m}$ in size were stained with haematossylin and eosin and then evaluated under the microscope at $50 \times$ magnification, using a $10 \times 10$ graticule to measure the number of foci per $\mathrm{mm}^{2}$. A focus was defined as an accumulation of at least 50 inflammatory cells. The percentage of plasma 
cells in the foci, and the presence of duct alterations or fibrosis were additional changes to be recorded.

SGS was to be performed using a gammacamera apparatus, taking sequential scintigrams of the head of the patient (immobilised in a posterior position) after the intravenous injection of $10 \mathrm{mCi}$ sodium pertechnetate ${ }^{99} \mathrm{Tc}^{\mathrm{m}}$. Scintigrams were to be taken at two minute intervals for the first 12 minutes and then at 10 minute intervals for the following 60-80 minutes. The pattern of tracer uptake in the salivary glands and its excretion into the oral cavity were classified according to Shall et $a l^{21}$ in one of the following four classes:

(1) Normal, when there was a rapid uptake of the tracer by the glands, with a progressive increase in concentration in the first 10 minutes and prompt excretion into the oral cavity within 20-30 minutes, until oral activity raised glandular activity at the end of the study;

(2) Mild/moderate involvement, when there was delayed uptake by the glands, or oral excretion of the tracer into the oral cavity, or both, and if at the end of the scintigraphic study oral activity was approximately equal to the tracer concentration in the glands;

(3) Severe involvement when tracer uptake by the salivary glands was considerably reduced and delayed, and oral activity was not always evident at the time of the final, static reading;

(4) Very severe involvement, when active concentration of the tracer into the gland and excretion into the mouth were practically absent.

The recommended procedure for PS was the following: after catheterisation of the Stensen's duct (preferably of the right gland), $2 \mathrm{ml}$ of hydrosoluble contrast media were slowly injected and antero-posterior and lateral sialograms immediately taken. The presence of dilatations in the salivary ducts was graded as follows: $^{22} 23$ punctate if less than $1 \mathrm{~mm}$ in size; globular if uniform and 1 to $2 \mathrm{~mm}$ in size; and cavitary if irregular and $>2 \mathrm{~mm}$ in size. A destructive pattern was defined as complete

Table 3 Demographic data on the SS patients and controls included in the study, and number of patients, divided by disease group, who underwent each of the ocular and oral diagnostic tests

\begin{tabular}{lllll}
\hline & Primary SS & Secondary SS & CTD no SS & Controls \\
\hline Total number of patients & 246 & $201 \dagger$ & $113 \dagger$ & 133 \\
Sex ratio (M/F) & $13 / 233$ & $12 / 189$ & $16 / 97$ & $12 / 121$ \\
Mean (SD) age (years) & $54(14)$ & $56(13)$ & $48(17)$ & $50(14)$ \\
Median age (years) & 55 & 58 & 50 & 51 \\
& & & & \\
Number of patients who had: & 228 & 185 & 102 & 118 \\
Schirmer's-I-test & 183 & 144 & 62 & 76 \\
Rose Bengal score & 173 & 127 & 59 & 77 \\
Break up time & 151 & 104 & 51 & 61 \\
Lacrimal lactoferrin test & 131 & 111 & 65 & 71 \\
Unstimulated saliva collection & 103 & 84 & 42 & 45 \\
Stimulated saliva collection & 210 & 154 & 63 & 69 \\
Minor salivary gland biopsy & 138 & 93 & 43 & 50 \\
Salivary gland scintigraphy & 77 & 55 & 21 & 29 \\
Parotid sialography & & &
\end{tabular}

${ }^{\star}$ CTD no SS = connective tissue disease without SS

TThere were 41 patients with systemic lupus, 102 with rheumatoid arthritis, 29 with systemic sclerosis, five patients with polymyositis or dermatomyositis, 12 with mixed connective tissue disease, and 12 with other CTDs.

$¥$ The CTD no SS group composed 49 patients with systemic lupus, 34 with rheumatoid arthritis 11 with systemic sclerosis, seven with polymyositis or dermatomyositis, four with mixed connective tissue disease, and eight with other CTDs. destruction of the gland architecture, simulating an invasive neoplastic process.

For the patient selection each participating centre was asked to enroll 40 consecutive patients subdivided as follows: 10 patients with primary SS, 10 with secondary SS, that is, patients with SS and an associated connective tissue disease (CTD), 10 with CTD but without SS, and 10 control patients. As it was agreed that no single diagnostic tool is able to establish a preliminary diagnosis of SS, the initial classification of every patient as SS or non-SS, and his inclusion in the corresponding disease group, was made solely on the basis of the clinical judgement of the observer and independently of any single diagnostic parameter. This procedure was similar to the one used by the American College of Rheumatology for the revision of classification criteria for rheumatoid arthritis. ${ }^{9}$ The diagnosis of each CTD was to be made on the basis of well defined and commonly accepted classification criteria. ${ }^{9-11} 2425$ In the selection of the control patients it was recommended to choose subjects who had also been seen by an expert on SS and for whom a complete work up could be justified since they were complaining of ophthalmological or oral manifestations which could simulate the clinical features of SS.

\section{DATA ANALYSIS}

Data from the participating centres was collected and entered into a database developed from standard software (Fox Base +/Mac, Fox Software), running on a Macintosh II computer (Apple Inc). The accuracy of each test in classifying the SS and non-SS patients was analysed using $2 \times 2$ tables. To reduce the possibility of selection bias, only data from centres which provided an adequate number of both SS patients and non-SS controls and which performed most of the diagnostic tests included in the study protocol in both groups were taken into account to determine the sensitivity and specificity of each tests.

The degree of agreement between the results obtained from the different diagnostic tests in the patients and controls was quantified using Cohen's kappa ${ }^{26}$ and Gower's similarity coefficient. ${ }^{27}$ Values of kappa greater than $0 \cdot 75$ were taken to be indicative of strong agreement; between 0.40 and 0.74 fair to good agreement, and below 0.40 poor agreement. The similarity coefficient was obtained by dividing the number of concordant results by the total number of (concordant plus discordant) observations.

\section{Results}

Twenty two centres from 11 countries provided data on a total of 447 SS patients and 246 controls. Demographic data and a summary of the tests performed for each disease group are reported in table 3 . In computing the sensitivity and specificity of the questionnaire items and the ocular and oral tests, we excluded the cases from eight centres as they did not enroll an adequate number of disease 
Table 4 Sensitivity and specificity of each ocular and oral test calculated in 136 SS patients and 118 controls provided by seven centres. They were 74 patients with primary SS [mean (SD) age 53.5 (13.6) years], 62 patients with secondary SS [mean (SD) age 53.5 (14.2) years], 60 patients with CTDs without SS [mean (SD) age 49.8 (17.6) years], and 58 controls [mean (SD) age $51.7(13 \cdot 3)$ years]. The group of patients with secondary $S S$ included 12 patients with systemic lupus, 28 with rheumatoid arthritis, nine with systemic sclerosis, two patients with polymyositis or dermatomyositis, eight with mixed connective tissue disease, and three with other associated diseases. The group of patients with $C T D$ s without SS included 15 patients with systemic lupus, 25 with rheumatoid arthritis, eight with systemic sclerosis, six patients with polymyositis or determatomyositis, three with mixed connective tissue disease, and one with mixed cryoglobulinaemia

\begin{tabular}{lllll}
\hline & Sensitivity & Specificity & SS patients & Controls \\
\hline Schirmer's-I-test & $76 \cdot 9$ & $72 \cdot 4$ & 134 & 116 \\
Lacrimal lactoferrin & $78 \cdot 4$ & $67 \cdot 6$ & 111 & 74 \\
Rose Bengal score & $64 \cdot 3$ & $81 \cdot 7$ & 126 & 93 \\
Break up time & $77 \cdot 8$ & $38 \cdot 9$ & 126 & 90 \\
& & & & \\
Unstimulated whole saliva collection & $56 \cdot 1$ & $80 \cdot 7$ & 123 & 83 \\
Stimulated whole saliva collection & $66 \cdot 4$ & $56 \cdot 4$ & 116 & 78 \\
Minor salivary gland biops`* & $82 \cdot 4$ & $86 \cdot 2$ & 125 & 87 \\
Salivary gland scintigraphy & $87 \cdot 2$ & $78 \cdot 9$ & 94 & 57 \\
Parotid sialography & $78 \cdot 6$ & 100 & 84 & 50 \\
\hline
\end{tabular}

${ }^{\star}$ focus score $\geqslant 1$.

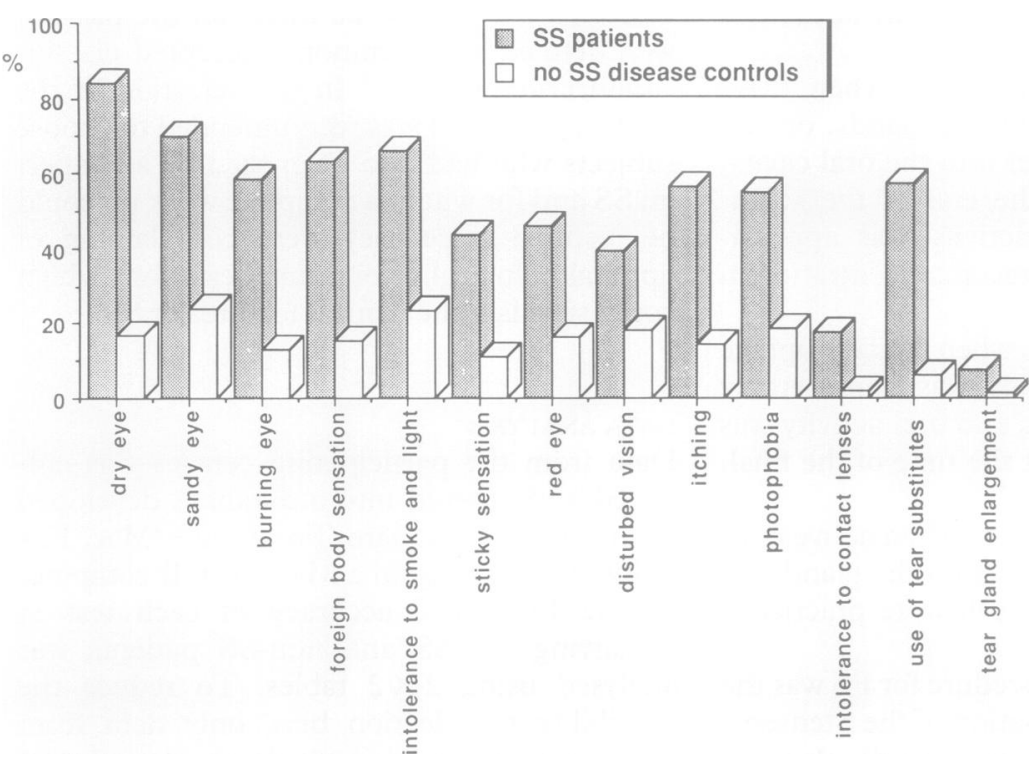

Figure 1 Prevalence of different ocular symptoms in patients with Sjögren's syndrome and in disease controls. Symptoms were recorded using a standard questionnaire for dry eyes (see table 1).

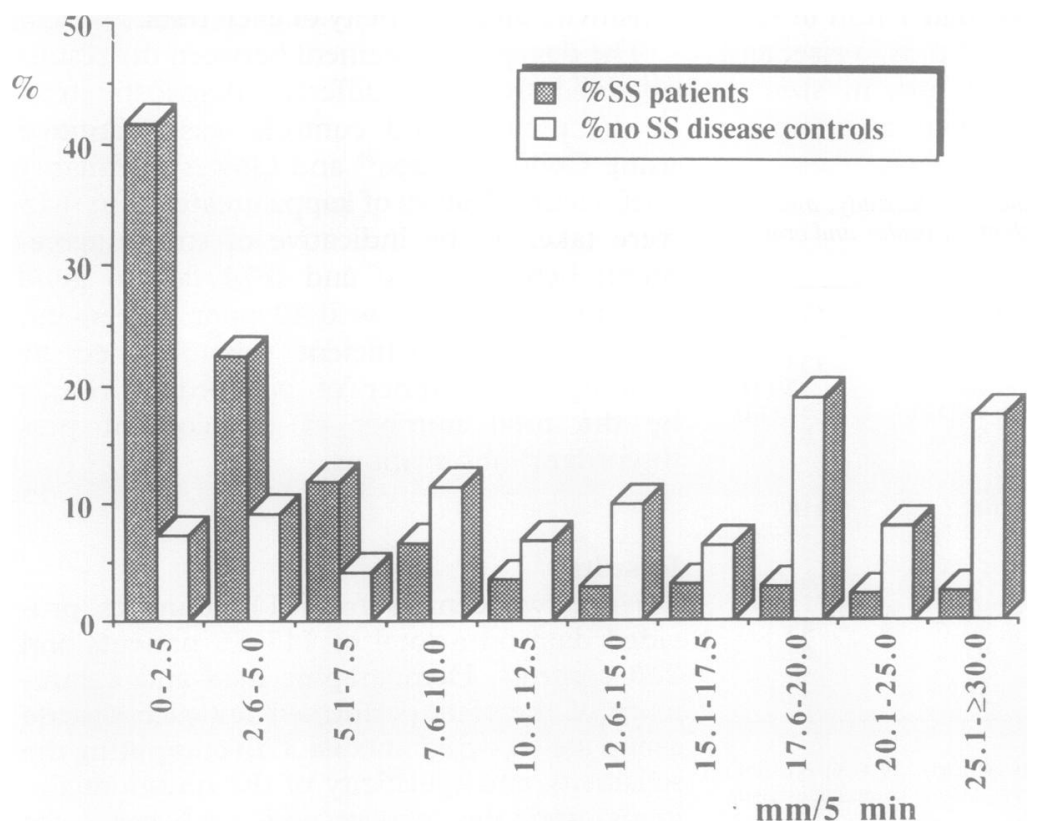

Figure 2 Distribution of Schirmer's-I-test values observed in patients with Sjögren's syndrome and in controls. controls ( $<60 \%$ of the number of SS patients). We then took into account only centres which rigorously followed the study protocol, filling in the questionnaires and performing the entire sequence of both ocular and oral tests in most of the SS patients and controls (that is, centres $3,5,6,7,10,23,24)$. Table 4 reports the composition of this final study population, clinical and epidemiological data of different disease groups, and the sensitivity and specificity calculated for each ocular and oral test.

OPTHALMOLOGICAL COMPLAINTS IN SS When the questionnaire for dry eye was analysed in terms of power of the different items to discriminate between SS patients and disease controls, item 1 (feeling of dry eye) and item 2 (feeling of sand in the eye) showed the highest accuracy $(82.7 \%$ and $73.6 \%$ respectively, with a sensitivity of $84.9 \%$ and $73.5 \%$ and a specificity of $80.0 \%$ and $73.8 \%$, respectively).

The prevalence of subjective symptoms of ocular involvement in patients with SS compared with disease controls is shown in fig 1 . When the prevalence of ocular symptoms in different disease groups was compared, it is worth noting that ocular symptoms were more frequently recorded in the patients with primary SS than in those suffering from SS associated with another CTD. For some of the symptoms, such as sensation of a foreign body or sand in the eye, burning sensation, intolerance to smoke and light, and the need for tear substitutes, this difference was statistically significant $(p<0.01$ for the latter item, $\mathrm{p}<0.05$ for the others).

\section{DIAGNOSTIC ACCURACY OF THE}

OPHTHALMOLOGICAL TESTS (SEE ALSO TABLE 4) The results obtained from the ScT in patients with SS (primary or secondary) and without SS are reported in fig 2 . When $5 \mathrm{~mm} / 5$ minutes of wetted paper was considered the cut off value, this test showed a sensitivity of $76.9 \%$ and a specificity of $72 \cdot 4 \%$. Sensitivity rose to $83.6 \%$, but specificity dropped to $69.8 \%$ if $10 \mathrm{~mm} / 5$ minutes was chosen as the cut off value. Although most of the SS patients had reduced lacrimal flow (ScT below the normal limits), there were patients with completely normal lacrimal secretion and some had an ScT $>10 \mathrm{~mm} / 5 \mathrm{~mm}$ (see fig 2).

The RBS distribution in the SS patients compared with that in the controls is shown in fig 3. Considering a score $\geqslant 4$ in at least one eye as abnormal, ${ }^{15}$ this test had a specificity of $81 \cdot 7 \%$ and a sensitivity of $64 \cdot 3 \%$.

Figure 4 shows that there was a large overlap in the distribution of BUT values in the SS patients and controls. When $\leqslant 10 \mathrm{sec}$ was taken as the cut off value for the break up of the fluorescinated lacrimal film, BUT appeared to be a sensitive $(77 \cdot 8 \%$ ), but not specific $(38.9 \%)$ test.

The distribution of TFLL in the two populations also largely overlapped (fig 5 ). The cut off value of $1 \cdot 1 \mathrm{~g} / \mathrm{L}$ suggested in the 


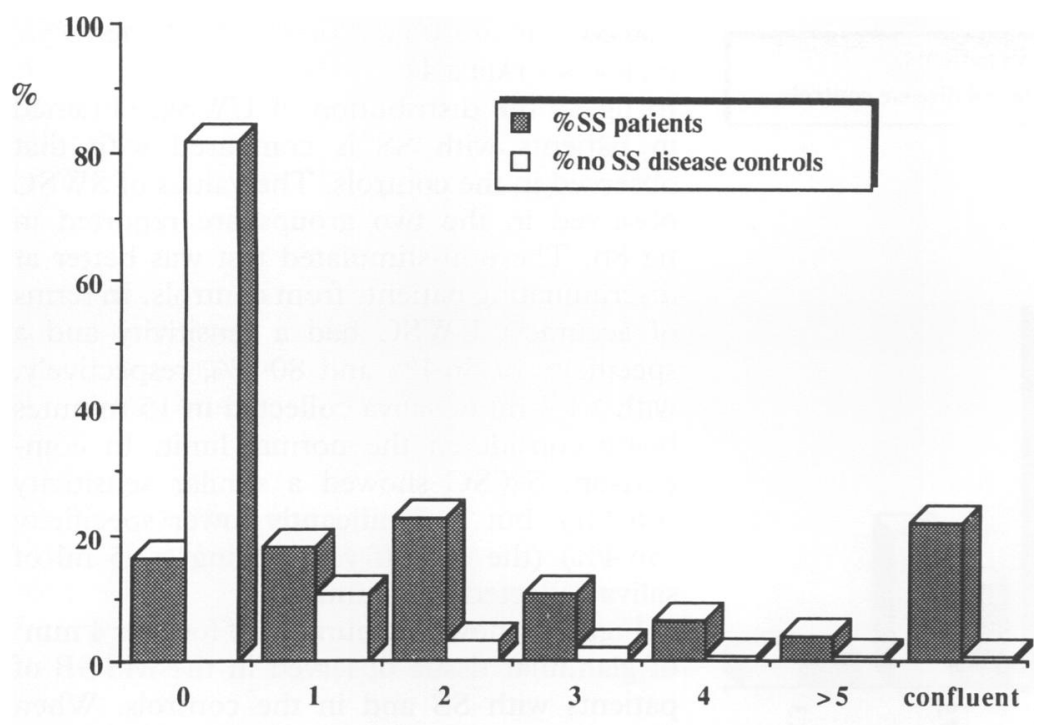

foci/4sqmm an acceptable degree of concordance (Cohen's kappa $>0.40$ ); all the other tests showed very poor agreement.

INFLUENCE OF AGE ON THE RESULTS OF THE OPHTHALMOLOGICAL TESTS

When the control population was analysed separately, both the ScT and TFLL values were found to be inversely correlated with age $(\mathrm{r}=0.18, \mathrm{p}<0.01$ and $\mathrm{r}=0.21, \mathrm{p}<0.03$, respectively). A detailed analysis by age group showed a significant decrease in subjects more than 55 years of age (fig 6). A similar trend was also noted for BUT, although the correlation with age was less significant $(r=0 \cdot 18$, $p<0.04)$, and the change was limited to the elderly population (over 65), being not progressive with the increase of age. On the contrary RBS did not seem to be influenced by age.

Figure 3 Distribution of rose Bengal scores obtained in patients with Sjögren's syndrome and in controls.

commercial kit was not particularly reliable in distinguishing SS patients from controls; 87 of 111 patients $(78.4 \%)$ and 50 of 74 controls $(67 \cdot 6 \%)$ were correctly classified.

AGREEMENT BETWEEN THE

OPHTHALMOLOGICAL TESTS

When the various ophthalmological tests were compared (table 5), only ScT and RBS showed

Table 5 Comparison between the different tests for ocular involvement in patients with SS and in controls. The degree of agreement between the results, each test being dichotomously defined as positive or negative, is expressed by means of Cohen's kappa (values reported on the left in each box), and Gower's similarity coefficient (values on the right, in italics)

\begin{tabular}{lllllllll}
\hline & Schirmer's-1-test & Lacrimal lactoferrin & Rose Bengal score & \multicolumn{2}{l}{ Break up time } \\
\hline Schirmer's-l-test & 1 & 1 & 0.374 & 0.699 & 0.415 & 0.706 & 0.240 & 0.645 \\
Lacrimal lactoferrin & & & 1 & 1 & 0.399 & 0.692 & 0.335 & 0.706 \\
Rose Bengal score & & & & & 1 & 1 & 0.251 & 0.617 \\
Break up time & & & & & & & 1 & 1 \\
\hline
\end{tabular}

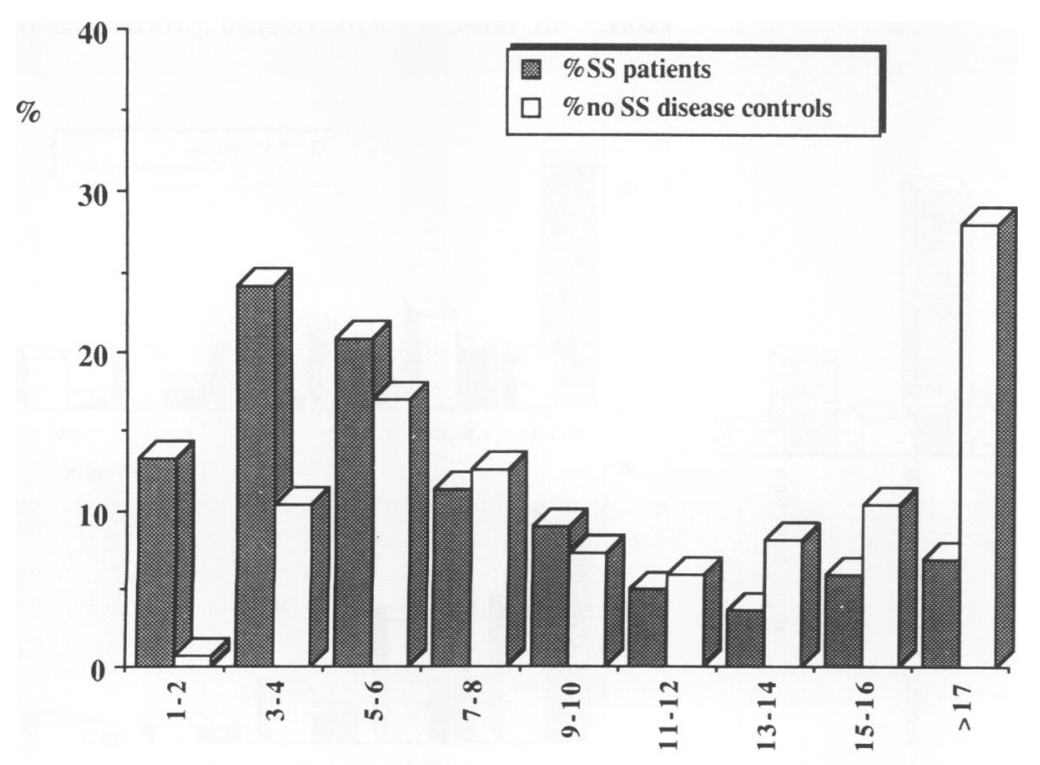

time (sec)

Figure 4 Distribution of tear break up times obtained in patients with Sjögren's syndrome and in controls.

\section{OPHTHALMOLOGICAL TESTS IN PRIMARY AND} SECONDARY SS

The ophthalmological tests showed less frequently and less extensively pathological those with primary SS. When the mean values for the two groups were analysed, these differences were statistically significant for TFLL (Student's $t=2 \cdot 5, \mathrm{p}<0.02$ ), BUT $(t=2.75, \mathrm{p}<0.01)$, RBS $(t=3.32, \mathrm{p}<0.001)$, but not for ScT $(t=1 \cdot 86, \mathrm{p}=0 \cdot 063)$. When the results of the ocular tests for the different CTDs associated with secondary SS were analysed and compared, no differences in the pattern of ophthalmological involvement were found.

ORAL COMPLAINTS IN SS

Figure 7 shows the prevalence of subjective symptoms of oral involvement in patients with SS and in disease controls. Items 1 (feeling of dry mouth), 2 (difficulties in swallowing dry food), and 6 (feeling of dryness when breathing or eating) from the questionnaire were the complaints with the highest discriminating power between SS patients and disease controls (accuracy 81.8, 74.7 and $74.4 \%$, sensitivity $81.4,62.3$ and $62.5 \%$, specificity $82.4,89.5$ and $90.2 \%$, respectively). The complaint of recurrent salivary gland enlargement (item 4) had low sensitivity $(36.4 \%)$, but very high specificity $(98.1 \%)$.

Among the different disease groups all of the symptoms of oral involvement, with the exception of item 7 (recurrent fungal infection in the mouth), were more frequently noted in the patients with primary SS than in those with the secondary disease. This difference was particularly significant for the symptom of recurrent salivary gland enlargement $(47 \cdot 1 \%$ in primary $S S v 21 \cdot 2 \%$ in secondary SS, $p<0.0001$ ), and that of the need for water or a saliva substitute $(60.0 \%$ in primary SS $v 43.4 \%$ in secondary SS, $\mathrm{p}<0.001)$. results in patients with secondary SS than in 


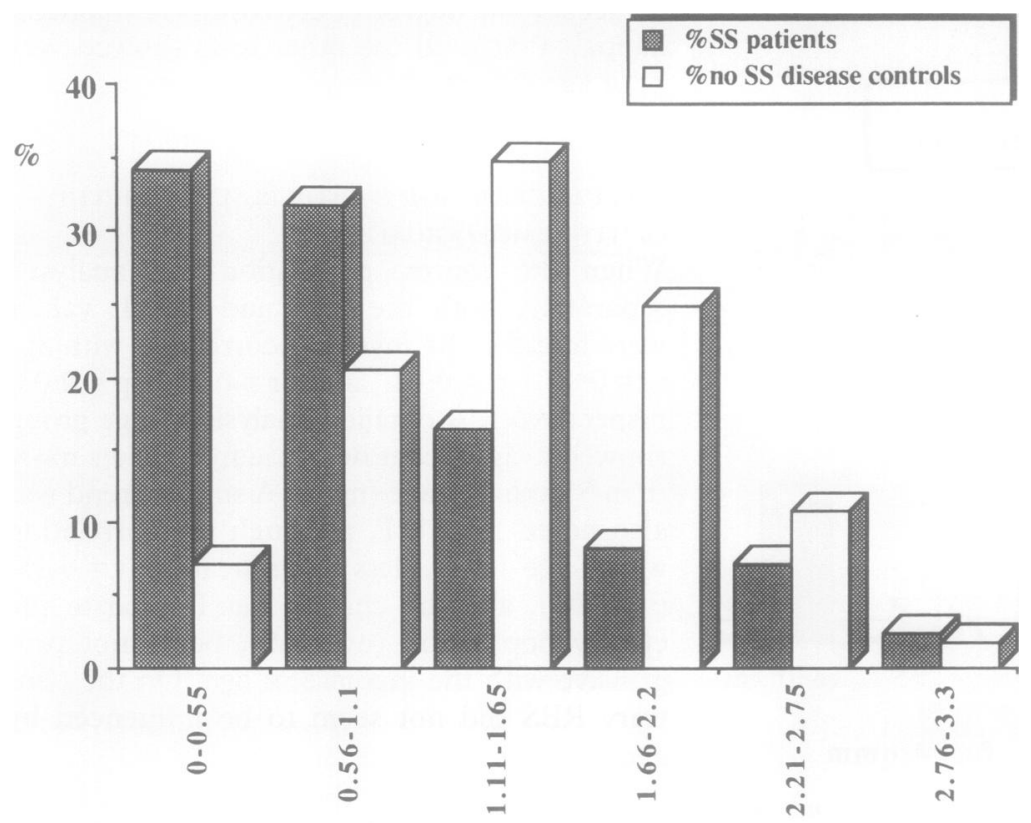

$\mathrm{g} / \mathrm{L}$

Figure 5 Distribution of lacrimal lactoferrin values observed in patients with Sjögren's syndrome and in controls.

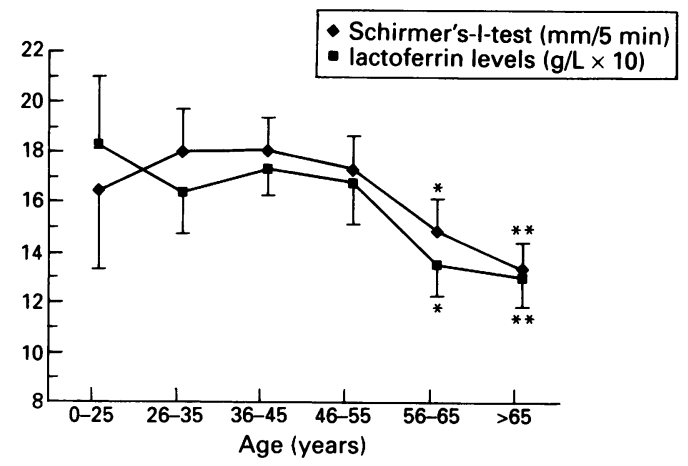

Figure 6 Variation with age of Schirmer's-I-test and the lacrimal lactoferrin values [reported as the mean (SE) value] in controls, showing a significant reduction in both parameters in individuals over $55\left({ }^{*} p<0.05\right.$ and $\star_{*}<0.02$ with respect to the 35-45 year old group).

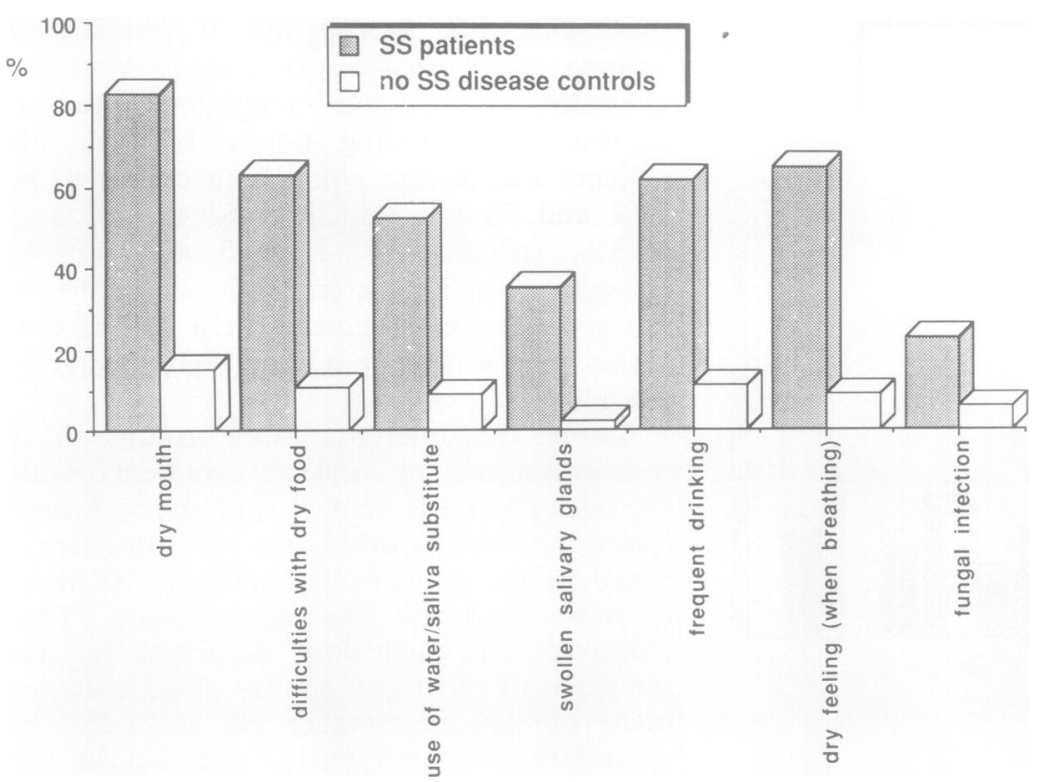

Figure 7 Prevalence of different oral symptoms in patients with Sjögren's syndrome and in disease controls. Symptoms were recorded using a standard questionnaire for dry mouth (see table 2).
DIAGNOSTIC ACCURACY OF THE ORAL TESTS

(SEE ALSO TABLE 4)

In fig 8a the distribution of UWSC obtained in patients with SS is compared with that observed in the controls. The values of SWSC observed in the two groups are reported in fig $8 \mathrm{~b}$. The non-stimulated test was better at discriminating patients from controls. In terms of accuracy, UWSC had a sensitivity and a specificity of $56 \cdot 1 \%$ and $80.7 \%$, respectively, with $>1.5 \mathrm{ml}$ of saliva collected in 15 minutes being considered the normal limit. In comparison, SWSC showed a similar sensitivity $(66.4 \%)$, but a significantly lower specificity $(56.4 \%$ ) (the cut off value being $>3.5 \mathrm{ml}$ of saliva collected in 5 minutes).

Figure 9 shows the number of foci per $4 \mathrm{~mm}^{2}$ of glandular tissue observed in the MSGB of patients with SS and in the controls. When the presence of at least 1 focus $/ 4 \mathrm{~mm}^{2}$ (focus score $\geqslant 1$ ) was considered as sufficient to classify an SS patient, the sensitivity and specificity of MSGB as a diagnostic tool for this disorder were $82 \cdot 4 \%$ and $86 \cdot 2 \%$, respectively. If, on the contrary, only the presence of more than 1 focus $/ 4 \mathrm{~mm}^{2}$ (focus score $>1$ ) was taken to be indicative of a diagnosis of SS, as suggested by other authors, ${ }^{19} 2829$ we obtained a higher specificity $(95.4 \%)$, but a significant decrease in sensitivity $(63 \cdot 2 \%)$.

When the results obtained for the four disease groups were separately analysed it was noted that $28.6 \%$ of the CTD patients classified as not having SS had a focus score $\geqslant 1$, while $24 \cdot 0 \%$ of the CTD patients included in the secondary SS groups did not show any inflammatory focus in MSGB.

The results of the SGS, following the scoring system suggested by Shall $e t a l,{ }^{21}$ are reported in table 6 . The overall sensitivity and specificity of this diagnostic procedure was $87 \cdot 2 \%$ and $79.0 \%$, respectively.

The different sialographic patterns observed in the four disease groups are reported, using the classification suggested by Rubin and Holt, ${ }^{22}$ in table 7 . The overall prevalence of

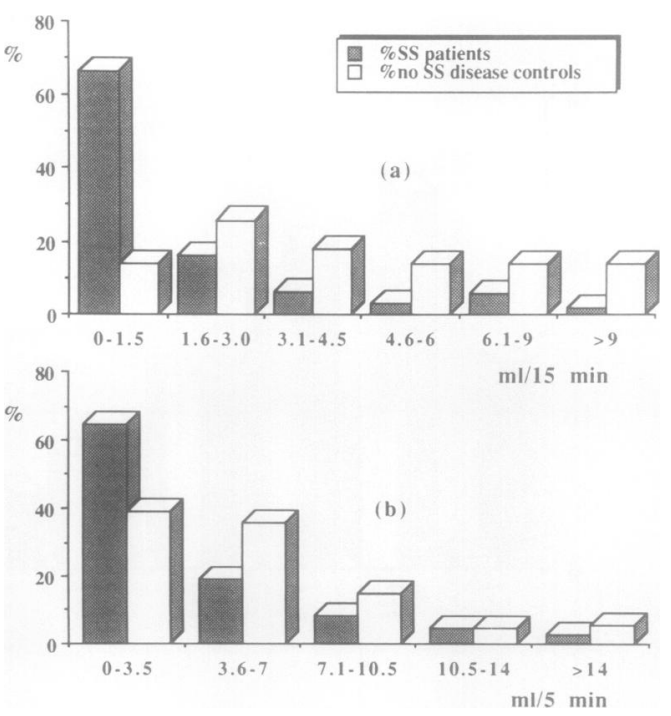

Figure 8 Distribution of the values for unstimulated (a) and stimulated (b) whole saliva collection, obtained in patients with Sjögren's syndrome and in controls. 
Table 6 Number and prevalence of SS patients and controls in whom SGS gave normal and abnormal results (these latter subdivided by grade of involvement)

\begin{tabular}{lcccc}
\hline & Primary SS & Secondary SS & CTD no SS & Controls \\
\hline Class 1 (normal result) & $24(17 \cdot 39 \%)$ & $23(24 \cdot 73 \%)$ & $39(90 \cdot 70 \%)$ & $41(82 \cdot 00 \%)$ \\
Class 2 (mild/moderate involvement) & $52(37 \cdot 68 \%)$ & $46(49 \cdot 46 \%)$ & $2(4 \cdot 65 \%)$ & $4(8 \cdot 00 \%)$ \\
Class 3 (severe involvement) & $48(34 \cdot 78 \%)$ & $19(20 \cdot 43 \%)$ & $2(4 \cdot 65 \%)$ & $5(10 \cdot 00 \%)$ \\
Class 4 (very severe involvement) & $14(10 \cdot 14 \%)$ & $5(5 \cdot 38 \%)$ & $0(0 \cdot 00 \%)$ & $0(0 \cdot 00 \%)$ \\
& $138(100 \%)$ & $93(100 \%)$ & $43(100 \%)$ & $50(100 \%)$ \\
\hline
\end{tabular}

CTD no SS = Connective tissue disease without SS.

The classification of the scintigrams and the grading of involvement was carried out according to Shall et al. ${ }^{21}$

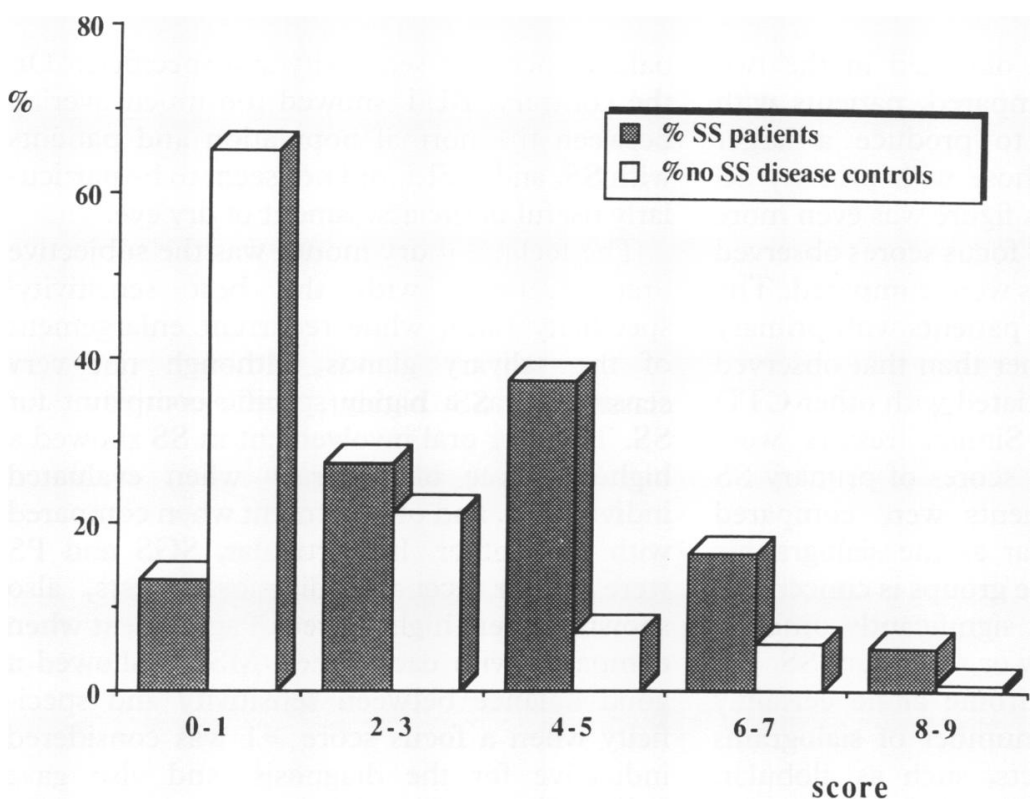

Figure 9 Distribution of sialoadenitis scores (number of foci/4 $\mathrm{mm}^{2}$ ) observed in minor salivary gland biopsies from patients with Sjögren's syndrome and from controls.

true positive results in SS patients was $78 \cdot 6 \%$, while that of true negative sialograms in the controls was $100 \%$. Thus sialography was the oral test with the highest specificity for SS.

AGREEMENT BETWEEN THE ORAL TESTS

The degree of agreement between the different tests for oral involvement is shown in table 8 . The highest level of accordance was found for PS and SGS (Cohen's kappa 0.741, with $87 \cdot 2 \%$ concordant results). Acceptable agreement between results was also found for MSGB and both PS and SGS, and for UWSC and PS (Cohen's kappa 0.43-0.55, and more than $70 \%$ concordant results). The agreement between UWSC and MSGB was somewhat lower; if one considered as diagnostic a focus score of $\geqslant 1$ or $\geqslant 2$, Cohen's kappa was 0.377 and 0.414 , and concordant results were 69.4 and $70 \cdot 7 \%$, respectively. The degree of agreement between UWSC and SWSC was not as high as might have been expected, considering that the two tests are essentially two different methods of measuring the same parameter.

INFLUENCE OF AGE ON THE RESULTS OF ORAL TESTS

As with the quantitative tests for tear production, the non-stimulated test for saliva collection showed reduced values in the normal elderly population. Patients over 65 years of age had significantly reduced mean (SD) UWSC values [3.34 (1.9) v $6.46(4.99) \mathrm{ml}$ 15 minutes observed in controls aged 35-45 years, $\mathrm{p}<0.01$ ]. A similar correlation with age was seen for SGS. False positive SGS were not found in controls under 35 years old, whereas they were observed in $12.5 \%$ of normal individuals aged 36-55 years and in 20\% of subjects over 56 years of age. However, these differences were not statistically significant because of the limited number of cases with false positive SGS. In contrast, no correlation with age was observed in the SWSC values in the normal population.

The presence of inflammatory foci in lip biopsies of patients without SS did not appear to be significantly correlated with age, whilst both the presence of duct alterations and fibrosis appeared to be related to ageing. Controls with fibrosis or duct abnormalities in their MSGB were significantly older than patients without these features $(t=3 \cdot 674, p<0 \cdot 001$ and $t=3 \cdot 122$, $\mathrm{p}<0.002$, respectively). This finding did not depend on the presence of inflammatory changes in lip biopsy, being also similar when patient population was taken into account.

Finally, the complete absence of false positive sialograms in the control groups seems to indicate that this diagnostic tool is not influenced by ageing.

ORAL TESTS IN PRIMARY AND SECONDARY SS The oral tests, like the ocular tests, showed less frequently and extensively abnormal results in the patients with secondary SS. When the

Table 7 Number and prevalence of SS patients and controls in whom PS gave normal and abnormal results (these latter subdivided by grade of involvement)

\begin{tabular}{lcccc}
\hline & Primary SS & Secondary SS & CTD no SS & Controls \\
\hline Score 0 (normal pattern) & $19(24 \cdot 68 \%)$ & $15(27 \cdot 27 \%)$ & $21(100 \cdot 00 \%)$ & $29(100 \cdot 00 \%)$ \\
Score 1 (punctate pattern) & $15(19 \cdot 48 \%)$ & $17(30 \cdot 91 \%)$ & $0(0 \cdot 00 \%)$ & $0(0 \cdot 00 \%)$ \\
Score 2 (globular pattern) & $25(32 \cdot 47 \%)$ & $13(23 \cdot 64 \%)$ & $0(0 \cdot 00 \%)$ & $0(0 \cdot 00 \%)$ \\
Score 3 (cavitary pattern) & $15(19 \cdot 48 \%)$ & $9(16 \cdot 36 \%)$ & $0(0 \cdot 00 \%)$ & $0(0 \cdot 00 \%)$ \\
Score 4 (destructive pattern) & $3(3 \cdot 9 \%)$ & $1(1 \cdot 82 \%)$ & $0(0 \cdot 00 \%)$ & $0(0 \cdot 00 \%)$ \\
& $77(100 \%)$ & $55(100 \%)$ & $21(100 \%)$ & $29(100 \%)$ \\
\hline
\end{tabular}

CTD no SS = connective tissue disease without SS. The classification of the sialograms and the grading of involvement was carried out according to Rubin and Holt ${ }^{22}$ 
Table 8 Comparison between the different tests of oral involvement in patients with SS and in controls. The degree of agreement between results, each test being dichotomously defined as positive or negative, is expressed by means of Cohen's kappa (values reported on the left), and Gower's similarity coefficient (values on the right in italics).

\begin{tabular}{|c|c|c|c|c|c|c|c|c|c|c|c|c|}
\hline \multirow{6}{*}{$\begin{array}{l}\text { UWSC } \\
\text { SWSC } \\
\text { Focus score } \geqslant 1 \\
\text { Focus score }>1 \\
\text { SGS } \\
\text { PS }\end{array}$} & \multicolumn{2}{|c|}{ UWSC } & \multicolumn{2}{|c|}{ SWSC } & \multicolumn{2}{|c|}{ Focus score $\geqslant 1$} & \multicolumn{2}{|c|}{ Focus score $>1$} & \multicolumn{2}{|l|}{$S G S$} & \multicolumn{2}{|l|}{$P S$} \\
\hline & 1 & 1 & $0 \cdot 454$ & $0 \cdot 726$ & $\begin{array}{l}0.377 \\
0.323\end{array}$ & 0.694 & $0 \cdot 414$ & $0 \cdot 707$ & $0 \cdot 366$ & $0 \cdot 680$ & $0 \cdot 438$ & 0.719 \\
\hline & & & & & $\begin{array}{l}0 \cdot 323 \\
1\end{array}$ & $\begin{array}{l}0.675 \\
1\end{array}$ & $\begin{array}{l}0 \cdot 297 \\
-\end{array}$ & 0.643 & $\begin{array}{l}0.221 \\
0.466\end{array}$ & $\begin{array}{l}0.610 \\
0.749\end{array}$ & $\begin{array}{l}0 \cdot 287 \\
0.438\end{array}$ & 0.642 \\
\hline & & & & & & & 1 & 1 & 0.473 & 0.732 & 0.515 & 0.757 \\
\hline & & & & & & & & & 1 & 1 & 0.741 & 0.872 \\
\hline & & & & & & & & & & & & \\
\hline
\end{tabular}

Focus score indicates the number of inflammatory foci per $4 \mathrm{~mm}^{2}$ of glandular tissue in MSGB. For other abbreviations see text.

mean values of UWSC obtained in the two disease groups were compared, patients with secondary SS seemed to produce a larger amount of saliva than those with primary SS $(\mathrm{t}=2.15, \mathrm{p}<0.05)$. This figure was even more evident when the MSGB focus scores observed in the two disease groups were compared. The number of foci found in patients with primary SS was significantly higher than that observed in patients with SS associated with other CTD $(t=4.54, p<0.0001)$. Similar results were obtained when the SGS scores of primary SS and secondary SS patients were compared $(t=2.7, p<0.01)$. As far as the sialographic pattern in the two disease groups is concerned, the mean score did not significantly differ in the patients with primary or secondary SS, but patients with sicca syndrome alone certainly showed more elevated number of sialograms with more severe aspects, such as globular, cavitary and destructive patterns. In only one oral test, the SWSC, was no significant difference seen in the results for the primary and secondary SS patients.

When the results obtained for the oral tests in patients with different CTD were analysed, only marginal differences were noted. For instance, patients with SLE and SS seemed to have a similar MSGB focus score to that observed in patients with SS alone, while the quantity of inflammatory infiltrates was considerably reduced in the patients with secondary SS associated with RA or with SSc. Furthermore, the results of the oral tests involving the major salivary glands, that is, PS and SGS, were considerably less abnormal in the patients with SS associated with RA.

\section{Discussion}

In this multi-centre European study on diagnostic criteria for SS, the accuracy of the most commonly used tests of oral and ocular involvement were investigated. In addition, standardised questionnaires for sicca complaints were used to select the most frequent and specific subjective symptoms of ocular and oral involvement in this disease. The study was carried out by 22 centres from 11 countries, using a single protocol and enrolling a total of 693 patients and controls.

Among the subjective ocular symptoms the feeling of dry eye and the sensation of sand in the eye were the ones which showed the highest discriminating power between SS patients and disease controls. Among the ophthalmological tests, RBS was the most specific for keratoconjunctivitis sicca, while ScT showed the best balance between sensitivity and specificity. On the contrary, BUT showed too much overlap between the normal population and patients with SS, and TFLL did not seem to be particularly useful in the assessment of dry eye.

The feeling of dry mouth was the subjective oral symptom with the best sensitivity/ specificity ratio, while recurrent enlargement of the salivary glands, although not very sensitive, was a highly specific complaint for SS. Tests for oral involvement in SS showed a higher degree of accuracy when evaluated individually, and of agreement when compared with each other. In particular, SGS and PS were rather accurate diagnostic tests, also showing a very high degree of agreement when compared with each other. MSGB showed a good balance between sensitivity and specificity when a focus score $\geqslant 1$ was considered indicative for the diagnosis, and also gave sufficiently concordant results with both PS and SGS. Finally, among the tests designed to quantify saliva production, UWSC was more reliable than SWSC in discriminating patients from controls, and gave more concordant results with the other tests for salivary involvement.

As far as the effect of age on the test results is concerned, it was found that secretion levels, as measured by ScT and TFLL for the eye, and UWSC for the mouth, were significantly reduced in the elderly population, while tests assessing morphological abnormalities, such as the MSGB and PS for the oral involvement and RBS for ocular involvement, were not related to ageing.

Finally, the results of all the tests of eye and oral involvement were less frequently and less extensively abnormal in the patients with secondary syndrome than in those with primary SS. This phenomenon cannot be ascribed to any particular patterns of exocrine gland involvement observable in patients with a specific associated CTD. The major salivary glands seemed to be less extensively involved in the patients with SS associated with RA, while oral involvement in the patients with SLE and associated secondary SS appeared to be the most similar to that observed in patients with the primary syndrome.

Xerostomia and xerophthalmia are the classic symptoms of SS, arising from a progressive reduction in lacrimal and salivary secretion due to inflammatory infiltration and consequent pathological changes in the corresponding glands. ${ }^{1}$ An assessment of ocular and oral involvement in SS is considered essential to the diagnosis of this disorder and is usually performed by measuring different parameters, 
such as the quantity and quality of secretions and morphological changes in the glands.

The secretions can be measured quantitatively by Schirmer's test for the eye $\mathrm{e}^{14}$ and by collecting saliva from the mouth. ${ }^{18}$ These tests, although relatively simple and non-invasive, seem not to be particularly specific and not especially sensitive. ${ }^{30}{ }^{31}$ It is also well knownand it has been clearly confirmed in the present study-that tear secretion, as well as saliva production, may be physiologically reduced in the elderly population ${ }^{32}{ }^{33}$. It would therefore be reasonable to establish lower cut-off values for the tests addressed to quantify saliva and tear production when administered in an elderly population.

More recently, measurement of the tear lactoferrin level ${ }^{17}$ has been proposed as a sensitive method to quantify lacrimal production, similar to that which has previously been suggested for lysozyme detection in tears and saliva. ${ }^{34-35}$ The present multi-centre study does not entirely confirm that, in comparison with other tests, TFLL is a more valid measure of tear production. This may be due to the not entirely reliable results obtained by two participating centres. Excluding these from the computation, the Cohen's kappa value obtained by comparing TFLL and ScT rises from 0.374 to $0 \cdot 442$. However, the fact that these centres had generated unreliable results suggests that the supposed greater precision of the TFLL ${ }^{17}$ could partly be reduced by its low feasibility as a screening test. Conversely, the observation that about $15 \%$ of SS patients had an ScT over $10 \mathrm{~mm} / 5$ minutes (although it might be supposed that these are patients with a prevalent oral component and only mild ocular involvement), confirms that ScT, as well as most of the ocular tests proposed, are probably not very reliable. ${ }^{30}$

The quality of tear production and more specifically the stability of this secretion is commonly tested by BUT, ${ }^{36}$ while abnormalities on the eye surface arising from a lack or reduction of the protective lacrimal film, are usually detected by the rose Bengal test. Contrasting results, however, have been obtained on their sensitivity and specificity as diagnostic tests for SS. ${ }^{37} 38$ In this study BUT did not demonstrate sufficient power to discriminate between SS patients and controls, whilst RBS, ${ }^{15}$ a quantified version of the original rose Bengal test, ${ }^{39}$ proved suitable for this purpose, since it was the most specific ocular test. These figures confirm previous results obtained in a single centre on a more limited number of cases. ${ }^{40}$

MSGB, SGS and PS are the tests most frequently used to explore pathological or more overtly anatomical changes in the minor or major salivary glands. ${ }^{41}$ MSGB is certainly the test most widely used and, given its high specificity, it has been suggested as a potential single diagnostic criterion for SS. ${ }^{5} 719$ This proposal is not completely convincing, since there is some evidence that an abnormal MSGB may also be found with significant frequency in conditions other than $\mathrm{SS}^{42-47}$ and even in normal individuals. ${ }^{48}{ }^{49}$ Moreover, it has been shown that a certain number of patients with SS may have a negative biopsy: this is particulary true when a focus score $>1$ is assumed to be positive. In previous reports ${ }^{28}$ 50-52 a considerable number of patients with SS did not fulfil this criterion. These observations were confirmed in the present study, where about one third of the SS patients did not show a lymphocytic focus score $>1$, and more than $25 \%$ of those patients with a CTD but not SS had a focus score $\geqslant 1$.

That the tests exploring the major salivary gland tests were more specific than the histological investigation of the minor glands is not completely surprising and has already been observed in other studies. ${ }^{53-55}$ However MSGB, particularly when the presence of at least one inflammatory focus $4 \mathrm{~mm}^{2}$ is accepted as indicative of the diagnosis of SS, remains a very useful test. In addition, recent work suggests that some immunohistological findings may improve the diagnostic accuracy of this procedure. ${ }^{56-58}$

The present study indicates that the results of the salivary gland (MSGB and PS) and ocular (RBS) tests are not influenced by the age of the patient, thus confirming their higher specificity in the diagnosis of SS. ${ }^{19} 3654$ These results do not agree with previous reports, where the presence of non-specific inflammatory changes in MSGB has been found to increase with age. ${ }^{59}$ This point remains to be clarified, however, since contradictory results have been obtained in necropsy studies aimed at detecting non-specific sialoadenitis in normal subjects by lip biopsy. ${ }^{49} 6061$ There is a large body of evidence indicating that most histological abnormalities (other than inflammatory foci) are not related to SS, but are rather dependent on ageing. ${ }^{61}$ The results of the present study confirm this statement, showing that both acinar fibrosis and ductal abnormalities are linked to progressive, age-related involution of the minor salivary glands, and that they are observed in equal numbers of patients with and without SS.

The milder expression of the disorder seen in patients with associated disease in the present study, had already been observed by others. ${ }^{62-65}$ Some of the differences noted in the present as well as in previous studies between patients with primary and secondary SS can probably be ascribed to the diagnostic criteria employed to classify the patients in one of the two variants of the syndrome. In patients with CTD, it is likely that the presence of either oral or ocular involvement can be considered as indicative of associated SS, whereas both lacrimal and salivary gland involvement is commonly required to establish a diagnosis of primary SS. ${ }^{62}$ This hypothesis only partially explains, however, the differing expression of the disease in patients with sicca syndrome alone and in those with secondary SS. It is well known that some of the clinical aspects of primary SS, such as recurrent parotitis, have a different prevalence in patients with SS associated with RA and other CTD. ${ }^{63} 64$ This finding, which is confirmed in the present study, may explain the milder involvement of 
major salivary glands observed by us, and previously reported by others, ${ }^{66}$ in the group of patients with secondary SS. On the contrary, among the patients with SS and an associated CTD, those with SLE seemed to be closest to the patients with SS alone, in their expression of sicca syndrome. This observation is not surprising when one considers the genetic, clinical and serological similarities between SLE and SS, ${ }^{67}$ and the genetic and clinical differences between SS and other associated diseases. ${ }^{63} 6970$

The results of our study indicate that no single test of oral or ocular involvement is sufficiently sensitive and specific to form the basis for a diagnosis of SS. In addition, some of the tests used for the diagnosis of keratoconjunctivitis sicca and xerostomia do not seem to be sufficiently accurate for these purposes. Only the simultaneous positivity of various tests which the present study indicates as being appropriate diagnostic tools, together with the presence of subjective symptoms and serological abnormalities, allow sufficient accuracy in the diagnosis of this disorder. The preliminary classification criteria recently proposed for this disorder ${ }^{12}$ are based directly on these findings.

This study was carried out as a Preparatory Activity with the support of the Directorate General for Science, Research and Development (DG XII) of the Commission of the European Communities and COMAC Epidemiology, one of the expert advisory committees in the Medical and Health Research advisory committees in the Medical and Healt
Programmes of the EC (Contract MR4 $4^{\star}-0218-\mathrm{I}$ ).

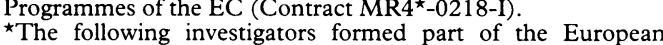
*The following investigators formed part of the European
Community Study Group on Diagnostic Criteria for Sjögren's

Syndrome:

Claudio Vitali, Walter Bencivelli, †Simonetta Chiellini, Salvatore De Vita, Maria Sciuto, Stefano Bombardieri: Clinical Immunology/Rheumatology Units and +Ophthalmology Unit, University of Pisa, Pisa, Italy; Haralampos M Moutsopoulos, Alexandros A Drosos, Fotini N Skopouli: Department of Medicine, University of Ioannina, Ioannina, Greece; Genesio Balestrieri, Susanna Braga: Division of Clinical Immunology, Spedali Civili, Brescia, Italy; Robert M Bernstein, Elaine M Spedali Civili, Brescia, Italy; Robert $M$ Bernstein, Elaine $M$ Hay: Department of Rheumatology and ARC Epidemiology
Research Unit, University of Manchester, Manchester, UK; Research Unit, University of Manchester, Manchester, UK;
Kirsten B Bjerrum: Ophthalmology Department, Rigshospitalet, Kirsten B Bjerrum: Ophthalmology Department, Rigshospitalet,
Copenhagen, Denmark; Joaquin Coll: Department of Internal Medicine, Autonomous University of Barcelona, Hospital de Mar, Barcelona, Spain; Michael Ehrenfeld, Yehuda Shoenfeld Research Unit of Autoimmune Diseases and Department of Medicine, Chaim Sheba Medical Center, Tel Hashomer, Israel; Pierre Y Hatron, Anne Janin: Department of Internal Medicine and Department of Pathology, University Hospital, Lille, France; David A Isenberg, Michael L Snaith: Bloomsbury Rheumatology Research Unit, Middlesex Hospital, Arthur Rheumatology Research Unit, Middlesex Hospital, Arthur Stanley House, London, UK; Joachim R Kalden: Institute of Rheumatology and Immunology, University of Erlangen, Erlangen, Germany; Louis Kater: Section of Clinical Immunology, Department of Internal Medicine, University Hospital, Utrecht, The Netherlands; Yrjö T Konttinen; Division of Rheumatic Diseases, Fourth Department of Hospital for Rheumatic Diseases, Bath, UK; Ravinder N Maini, Patrick J W Venables: The Kennedy Institute for Rheumatolog, Hammersmith, London, UK; Rolf Manthorpe: Rheumatology, Hammersmith, Lon Department of Rheumatology, Malmø Allmänna Sjukhus, Malmø, Sweden; Olivier Meyer: Division of Rheumatology, Xavier Bichat Medical Faculty, Paris, France; Pierantonio Ostuni, Silvano Todesco: Division of Rheumatology, Department of Internal Medicine, University of Padua, Padua, Italy; Yvon Pennec, Pierre Youinou: Clinics of Internal Medicine and Laboratory of Immunology, Brest University
Medical School Hospital, Brest, France; Jan U Prause: Eye Medical School Hospital, Brest, France; Jan U Prause: Eye Pathology Institute and Department TZ, University of Copenhagen, Copenhagen, Denmark; Andrea Richards, Serda and Pathology, Bristol Dental Hospital and School, Bristol, UK; Bernard Sauvezie: Rheumatology Service, Saint Jacques Hospital, Clermont Ferrand, France; Morten Schiødt: Hillerød Department of Oral Medicine and Oral Surgery, Institute of Pathology and Medicine, Royal Dental College, Copenhagen Denmark; Josef S Smolen: Centre for Rheumatic Diseases, 2nd Department of Medicine, Lainz Hospital, Vienna, Austria Moshe Tishler: Rheumatology Department, Ichilov Hospital Tel Aviv, Israel; Guido Valesini: Department of Internal Medicine, 'La Sapienza' University, Rome, Italy; Marie Medicine, 'La Sapienza' University, Rodicine, Saint-Antoine Hospital, Paris, France.
1 Moutsopoulos H M, Chused T M, Mann D L, et al. Sjögren's syndrome (sicca syndrome): current issues. Ann Intern Med 1980; 92: 212-26.

2 Mackie I A, Seal D V. The questionable dry eye. $\mathrm{Br} f$ Ophthalm 1981; 65: 2-9.

3 Schiødt $M$, Thorn J. Criteria for the salivary component of Sjögren's syndrome. A review. Clin Exp Rheumatol 1989; 7: 119-22.

4 Manthorpe R, Oxholm P, Prause J U, Schiödt M. The Copenhagen criteria for Sjögren's syndrome. Scand 7 Rheumatol 1986; Suppl 61: 19-21.

5 Skopouli F N, Drosos A A, Papaioannou T, Moutsopoulos H M. Preliminary diagnostic criteria for
Siögren's syndrome. Scand $\mathcal{F}$ Rheumatol 1986; Suppl 61: Sjögren.

6 Homma M, Tojo T, Akizuki M, Yagamata H. Criteria for Sjögren's syndrome in Japan. Scand $\mathcal{F}$ Rheumatol 1986 Suppl 61: $26-7$

7 Fox R I, Robinson C, Curd J C, Michelson P, Kozin F, Howell F V. Sjögren's syndrome: proposed criteria for classification. Arthritis Rheum 1986; 29: 577-85.

8 Vitali C, Bombardieri S. Diagnostic criteria for Sjögren's syndrome: the state of the art. Clin Exp Rheumatol 1990; 8/S-5: 13-7.

9 Arnett F C, Edworth S M, Bloch D A, et al. The American Rheumatism Association 1987 revised criteria for the classification of rheumatoid arthritis. Arthritis Rheum 1988; 31: 315-24

10 Tan E M, Cohen A S, Fries J F, et al. The 1982 revised criteria for the classification of systemic lupus erythematosus. Arthritis Rheum 1982; 25: 1271-7.

11 Masi A T, Rodnan G P, Medsger T A, et al. Preliminary criteria for the classification of systemic sclerosis (scleroderma). Arthritis Rheum 1980; 23: 581-90.

12 Vitali C, Bombardieri S, Moutsopoulos H M, et al. Preliminary criteria for the classification of Sjögren's syndrome. Results of an EEC prospective concerted syndrome. Results of an EEC prosp
action. Arthritis Rheum 1993; 36: 340-7.

13 Workshop on Diagnostic Criteria for Sjögren's syndrome. I. Questionnaires for dry eye and dry mouth. II. Manual of methods and procedures. Clin Exp Rheumatol 1989; 7: 212-9.

14 Haldberg G P, Berens C. Standardized Schirmer tear test kit. Am f Ophthalmol 1961; 51: 840-2.

15 van Bijsterveld O P. Diagnostic tests in the sicca syndrome. Arch Ophthalmol (Chicago) 1969; 82: 10-4.

16 Norn M S. Tear secretion in diseased eves. Acta Ophthalmol 1966; 44: 25-32.

17 Janssen P J, van Bijsterveld O P. A simple test for lacrimal gland function: a tear lactoferrin assay by radial immunodiffusion. Graefe's Arch Clin Exp Ophthalmol 1983; 220: $171-5$.

18 Heinze U, Birkhed D, Bijorn H. Secretion rate and buffer effect of resting and stimulated whole saliva as function of age and sex. Swed Dent f 1983; 7: 227-38.

19 Daniels T E. Labial salivary gland biopsy in Sjögren's syndrome. Assessment as a diagnostic criterion in 362 suspected cases. Arthritis Rheum 1984; 27: 147-56.

20 Daniels T E. Salivary histopathology in diagnosis of Sjögren's syndrome. Scand $\mathcal{F}$ Rheumatol 1986; Suppl 61: 36-43.

21 Shall G L, Anderson L G, Wolf R O, et al. Xerostomia in Sjögren's syndrome: evaluation by sequential scintigraphy. $\mathcal{F} A M A$ 1971; 216: 2109-16.

22 Rubin H, Holt $M$. Secretory sialography in diseases of the major salivary glands. Am $\mathcal{F}$ Roentgenol 1957; 77: 575-98.

23 Dijkstra P F. Classification and differential diagnosis of sialographic characteristics in Sjögren's syndrome. Semin Arthritis Rheum 1980;10: 10-7.

24 Sharp G C, Irvin W S, Tan E M, Gould R G, Holman H R Mixed connective tissue disease. An apparently distinct rheumatic disease syndrome associated with a specific antibody to an extractable nuclear antigen (ENA). $A m \mathcal{F}$ Med 1972; 52: 148-59.

25a Bohan A, Peter J B. Polymyositis and dermatomyositis. (First of two parts). N Engl f Med 1975; 292: 444-7.

25b Bohan A, Peter J B. Polymyositis and dermatomyosisitis. (Second of two parts). N Engl F Med 1975; 292: 403-7.

26 Cohen J. Weighted kappa: nominal scale agreement with provision for scaled disagreement or partial credit. Psychological Bulletin 1968; 70: 213-20.

27 Gower J C. Measures of similarity, dissimilarity, and distance. In: Kotz S and Johnson N L eds. Encyclopedia distance. In: Kotz $S$ and Johnson N L eds. Encyclopedia
of statistical sciences, vol 5 . New York, John Wiley, 1985.

28 Chisholm D M, Mason D K. Labial salivary gland biopsy in Sjögren's syndrome. I Clin Pathol 1968; 21: 656-60.

29 Greenspan J S, Daniels T E, Talal N, Sylvester R A. The histopathology of Sjögren's syndrome in labial salivary gland biopsies. Oral Surg Oral Med Oral Pathol 1974; 37: $217-29$.

30 van Bijsterveld O P, Macron A J. Sjögren's syndrome and tear function parameters. Clin Exp Rheumatol 1989; 7: 151-4.

31 Skopouli F N, Siouna-Fatourou H I, Ziciadis C, Moutsopoulos H M. Evaluation of unstimulated whole saliva flow rate and stimulated parotid flow as confirmatory tests for xerostomia. Clin Exp Rheumatol 1989; 7: 127-9.

32 Seal $D$ V. The effect of ageing and disease on tear constituents. Trans Ophthalmol Soc UK 1985; 104: 355-62.

33 Heft M W, Baum B J. Unstimulated and stimulated parotid flow rate in individuals of different ages. $\mathcal{F}$ Dent Res 1984; 63: $1182-5$. 
34 Van Bijsterveld O P. Standardization of the lysozyme test for the commercially available medium. Its use for the diagnosis of the sicca syndrome. Arch Ophthalmol (Chicago) 1974; 91: 432-4

35 Moutsopoulos H M, Karsh J, Wolf R O, Tarpley T M Tylendza A Papadopoulos N M. Lysozyme determination in parotid saliva from patients with Sjögren's syndrome. Am f Med 1980; 69: 39-42.

36 Vanley G T, Leopold I H, Greegg T H. Interpretation of tear film break-up. Arch Ophthalmol (Chicago) 1977; 95: 445-8.

37 Farris R L, Gilbard J B, Stuchell R N, Mandell I D. Diagnostic tests in keratoconjunctivitis sicca. The CLAO F 1983; 9: 23-8.

38 Holly F J. Physical chemistry of the normal and disordered tear film. Trans Ophthalmol Soc UK 1985; 104: 374-80.

39 Norm M S. Rose Bengal. In: Norm M S, ed. External eye. Methods of examination. Copenhagen, Scriptor, 1983 $60-4$

40 Paschides C A, Kitsios G, Karakostas K X. Psillas C Moutsopoulos H M. Evaluation of tear break-up time, Schirmer's-I-tests and rose bengal staining as confirmatory tests for keratoconjunctivitis sicca. Clin Exp Rheumatol 1989; 17: 155-7.

41 Scully C. Oral parameters in the diagnosis of Sjögren's syndrome. Clin Exp Rheumatol 1989; 7: 113-7.

42 Lindahl G, Hedfors E. Lymphocytic infiltrates and epithelial HLA-DR expression in lip salivary glands in connective tissue disease patients lacking sicca: prospective study. Br $\mathcal{F}$ Rheumatol 1989; 28: 293-8.

43 Lindahl G, Levfert A, Hedfors E. Periductal lymphocytic infiltrates in salivary glands in myasthenia gravis patients lacking Sjögren's syndrome. Clin Exp Immunol 1986; 66: 95-102.

44 Hansen B U, Lindgren S, Eriksson, et al. Clinical and immunological features of Sjögren's syndrome in patients with primary biliary cirrhosis with emphasis on focal with primary biliary cirrhosis with emphasis

45 Lindahl G, Lönnquist B, Hedfors E. Lymphocytic infiltrations of lip salivary glands in bone marrow recipients: a model for the development of histopathological changes in Sjögren's syndrome? f Autoimmun 1989; 2: 579-83.

46 Couderc L, D'Agay M, Danon F, Harzic M, Brocheriou C B, Clauvel J. Sicca complex and infection with human immunodeficiency virus. Arch Intern Med 1987; 147: 898-901.

47 Schiodt M, Greenspan D, Daniels T E, et al. Parotid gland enlargement and xerostomia associated with labial sialoadenitis in HIV-infected patients. $\mathcal{F}$ Autoimmun 1989 ; 2: $415-25$.

48 Takeda Y, Komori A. Focal lymphocytic infiltration in the human labial salivary glands: a postmortem study. $f$ Oral Pathol 1986; 15: 83-6.

49 De Wilde P C M, Baak J P A, van Houwelingen J C, Kater L, Slootweg P J. Morphometric study of histological changes in sublabial salivary glands due to aging process. 7Clin Pathol 1986; 39: 406-17.

50 Talal N, Asofsky R, Lightbody P. Immunoglobulin synthesis by salivary gland lymphoid cells in Sjögren's syndrome. fClin Invest 1970; 49: 49-54.

51 Anderson L G, Cummings N A, Asofsky R, et al. Salivary gland immunoglobulin and rheumatoid factor synthesis in Sjögren's syndrome: natural history and response to treatment. Am $\mathcal{F}$ Med 1972; 53: 456-63.

52 Franco A, Valesini G, Barnaba V, Silvagni C, Tiberti A, Balsano F. Class II MHC antigen expression on epithelial cells of salivary glands from patients with Sjögren's syndrome. Clin Exp Rheumatol 1987; 5: 199-203.
53 Marx R E, Hartman K S, Rethman K V. A prospective study comparing incisional labial and incisional parotid biopsies in the detection and confirmation of sarcoidosis, Sjögren's disease, sialosis and lymphoma. $f$ Rheumatol 1988; 15: 621-9.

54 Vitali C, Tavoni A, Simi U, et al. Parotid sialography and minor salivary gland biopsy in the diagnosis of Sjögren's syndrome: a comparative study of 84 patients. Rheumatol 1988;15: 262-7.

55 Pennec Y L, Leroy J P, Jouquan J, Lelong A, Katsikis $P$, Youinou P. Comparison of labial and sublingual salivary gland biopsies in the diagnosis of Sjögren's syndrome. Ann Rheum Dis 1990; 49: 37-9.

56 De Wilde P C M, Kater L, Baak J P A, van Houwelingen J C, Hené R J, Slootweg P J. A new and highly sensitive immunohistologic diagnostic criterion for Sjögren's immunohistologic diagnostic criterion for

57 Speight P M, Cruchley A Williams D M. Quantification of plasma cells in labial salivary glands: increased expression of IgM in Sjögren's syndrome. $\mathcal{F}$ Oral Pathol Med 1990, 19: $126-30$

58 Bodeutsch C, De Wilde P C M, Kater L, et al. Quantitative immunohistologic criteria are superior to the lymphocytic focus score criterion for the diagnosis of Sjögren's syndrome. Arthritis Rheum 1992; 35: 1075-87.

59 Syriänen $S$. Age related changes in structure of labial minor salivary glands. Age Ageing 1984; 13: 159-65.

60 Chisholm D M, Waterhouse J P, Mason D K. Lymphocytic sialoadenitis in the major and minor glands: a correlation in post-mortem study. $\mathcal{F}$ Clin Pathol 1970; 23: 690-4.

61 Scott J. Qualitative and quantitative observations on the histology of human labial salivary glands obtained postmortem. F Biol Buccale 1980; 8: 187-200.

62 Whaley $\mathrm{K}$, Williamson J, Chisholm D M, Webb J Mason D K, Buchanan W W. Sjøgren's syndrome. 1. Sicca components. $O 7 \mathrm{Med} 1973 ;$ 42: 279-304

63 Moutsopoulos H M, Webber B L, Vaglopoulos T P Chused T M, Decker J L. Differences in the clinical manifestations of sicca syndrome in the presence and manifestations of sicca syndrome in the presence and 733-6.

64 Drosos A A, Pennec Y L, Elisaf M, et al. Sjögren's syndrome in patients with CREST variant of progressive systemic scleroderma. $\mathcal{F}$ Rheumatol 1991; 18: 1685-8.

65 Andonopoulos A P, Skopouli F N, Dimou G S, Drosos A A Moutsopoulos H M. Sjögren's syndrome in systemic lupus erythematosus. $\mathcal{F}$ Rheumatol 1990; 17: 201-4.

66 Whaley K, Blair S, Low P S, Chisholm D M, Dick W C, Buchanan W W. Sialographic abnormalities in Sjögren's syndrome, rheumatoid arthritis, and other connective tissue diseases. A clinical radiological investigation tissue diseases. A clinical radiological investigation
using hydrostatic sialography. Clin Radiol 1972; 23: using hydr

67 Moutsopoulos H M, Klippel J H, Pavlidis, et al. Correlative histologic and serologic findings of sicca syndrome in patients with systemic lupus erythematosus. Arthritis Rheum 1980; 23: 36-40

68 Pease C T, Shattles P J, Charles P J, Venables P J W, Maini R N. Clinical serological, and HLA phenotype subsets in Sjögren's syndrome. Clin Exp Rheumatol 1989; 7: $185-90$.

69 Moutsopoulos H M, Mann D L, Johnson A H, Chused T M. Genetic differences between primary and Chused T M. Genetic differences between primary and 761-3.

70 Osial T A, Whiteside T L M, Buckingham R B, et al. Clinical and serologic study of Sjögren's syndrome in patients with progressive systemic sclerosis. Arthritis Rheum 1983; 26: 500-8. 